\title{
Tsafon
}

Revue d'études juives du Nord

$75 \mid 2018$

Exil des langues - Langues d'exil

\section{Lili Leignel, Je suis encore là. Rescapée de la Shoah et infatigable "Passeur de Mémoire »}

Danielle Delmaire

\section{(2) OpenEdition}

1 Journals

Édition électronique

URL : https://journals.openedition.org/tsafon/744

DOI : $10.4000 /$ tsafon.744

ISSN : 2609-6420

Éditeur

Association Jean-Marie Delmaire

Édition imprimée

Date de publication : 1 juin 2018

Pagination : 186-187

ISSN : 1149-6630

\section{Référence électronique}

Danielle Delmaire, «Lili Leignel, Je suis encore là. Rescapée de la Shoah et infatigable "Passeur de

Mémoire » », Tsafon [En ligne], 75 | 2018, mis en ligne le 06 mai 2019, consulté le 27 juin 2021. URL

http://journals.openedition.org/tsafon/744 ; DOI : https://doi.org/10.4000/tsafon.744

Ce document a été généré automatiquement le 27 juin 2021.

Tsafon. Revues d'études juives du Nord 


\title{
Lili Leignel, Je suis encore là. Rescapée de la Shoah et infatigable " Passeur de Mémoire »
}

\author{
Danielle Delmaire
}

\section{RÉFÉRENCE}

Lili Leignel, Je suis encore là. Rescapée de la Shoah et infatigable " Passeur de Mémoire ", Copymédia, 2017, 284 p., $20 €$

1 Quel écolier, quel collégien, quel lycéen du Nord et des Hauts-de-France ne connaît pas ou n'a pas entendu parler de «Madame Leignel » que beaucoup d'entre eux appellent affectueusement «Lili»? Elle est l'«infatigable Passeur de Mémoire» qui inlassablement depuis le début des années 1980, depuis que les négationnistes de la Shoah commencèrent à se faire entendre, témoigne de ce que fut la Shoah pour trois enfants, ses deux frères et elle-même, auprès des enfants qui n'ont pas connu ces années sombres. Le lecteur est averti dès la première page : «Ce livre est spécialement destiné aux élèves pour que le devoir de mémoire perdure à l'infini ». Ne pas oublier et surtout ne pas nier! Alors, à 86 ans, Lili Keller-Rosenberg, épouse Leignel (p. de garde) a un agenda surchargé car il y a: "nécessité de poursuivre aussi longtemps que possible mes témoignages devant les jeunes, c'est ma mission... indéfiniment » (p. 167).

2 Son récit, elle le déroule invariablement devant des classes, parfois des centaines de jeunes, toujours impressionnés par sa capacité à raconter sans faiblir et sans pathos excessif. Ce sont ses premières années à Roubaix où elle vit dans une famille aimante et unie : ses parents immigrés de Hongrie, elle l'aînée et ses deux frères, nés en 1933 et 1940. Lorsque la situation devient dangereuse pour les juifs, l'abbé Flipo parvient à disperser la famille dans différentes caches. Mais l'affection qui unit cette famille encourage les parents à se réunir, dans l'appartement, exceptionnellement pour l'anniversaire de la maman. C'est l'erreur : toute la famille est immédiatement arrêtée 
dans une rafle de septembre 1943 qui touche les juifs originaires de pays alliés du Reich, la Hongrie, l'Italie et la Turquie. Une quinzaine de personnes (enfants et adultes) sont détenus à Loos avant d'être internés à la terrible caserne Dossin à Malines, en Belgique, puis d'être déportés à Buchenwald pour les hommes et Ravensbrück pour les femmes accompagnées de leurs enfants (la liste a été publiée dans Tsafon, $\mathrm{n}^{\circ}$ 21, printemps 1995 , p. 29).

3 Trois enfants, dont le plus jeune a tout juste 3 ans (devenu adulte, il a soutenu une thèse sur les enfants dans la Shoah au début des années 2000), survivent alors dans les conditions inhumaines d'un camp de concentration où sont également internées des résistantes déterminées à survivre et à faire vivre ces enfants. Lili Leignel se souvient bien de G. de Gaulle, J. d'Alincourt ou encore de M. Desrumaux. Le courage de survie vient de la maman, Charlotte Keller, qui malgré cet enfer donne à ses enfants des leçons de dignité et les oblige à se laver chaque matin avant son départ pour une longue et exténuante journée de travail. Affamés, épuisés, malades, la maman et les enfants sont ensuite déportés à Bergen-Belsen qui n'est pas autre chose qu'un mouroir. La maman est alors atteinte du typhus et ne peut pas bénéficier d'un rapatriement immédiatement après la libération du camp. C'est une nouvelle épreuve pour les enfants qui ne peuvent plus bénéficier de son soutien moral. Les trois enfants se retrouvent à l'hôtel Lutétia, complètement perdus, voire ignorés des services sociaux accordés aux déportés. C'est Lili, elle-même qui a l'idée de contacter un membre de sa famille dont elle a conservé vaguement la trace.

4 Les enfants ne sont apaisés que par le retour de la maman bien affaiblie encore mais vivante. Ce qui n'est pas le cas du papa qui ne revient pas de Buchenwald. La réinsertion dans le Roubaix d'après-guerre n'est pas facile. L'appartement a été vidé. Courageusement la maman, aidée de voisins compatissants, reprend ses activités de couturière pour élever ses enfants.

5 Lili a témoigné dans les années 1950, elle a également fait partie d'associations d'anciens déportés, mais c'est lorsque des faussaires de l'histoire nièrent la réalité de la Shoah qu'elle décida de raconter, encore et encore sa survie à Ravensbrück et à BergenBelsen. Deux enseignants, Nadège Frémeaux et Loïc Cattiaux, au collège Jacques Prévert de Houdain (Pas-de-Calais) ont eu l'excellente idée de publier les souvenirs de Lili (ceux-ci ont déjà été publiés partiellement dans Tsafon, nº 9-10, été-automne 1992, p. 29-37) augmentés, et c'est là l'intérêt supplémentaire de l'ouvrage, des récits de ses témoignages dans diverses classes et aussi des lettres que les élèves ont envoyées à Lili pour la remercier et lui confier leurs émotions. Ce corpus peut devenir une source d'étude pour des historiens de la réception des témoignages de rescapés de la Shoah. Et l'on peut découvrir que, presque toujours, Lili a réussi son pari : convaincre les jeunes d'être vigilants et de refuser toute forme de discrimination, sociale, religieuse, ethnique... En cela, Lili Leignel née Rosenberg a bien mérité les insignes de chevalier de l'ordre national de la Légion d'Honneur (2011) et les insignes d'officier des palmes académiques (2016), reconnaissance de l'utilité de ses rencontres avec des milliers de jeunes (environ 10000 chaque année) pour le maintien de la démocratie et la lutte contre toutes formes de racisme y compris l'antisémitisme. 